\title{
Analisis Tata Kelola Teknologi Informasi Untuk Meningkatkan Mutu Sumber Daya Manusia Pada Dinas Tenaga Kerja Dan Transmigrasi Provinsi Nusa Tenggara Barat Menggunakan Framework COBIT 5
}

\author{
(Analysis of Information Technology Governance to Improve the Quality of Human \\ Resources in the Department of Labour and Transmigration, West Nusa Tenggara, \\ Using COBIT 5 Framework)
}

\author{
Azmi Yunda Chairani, Royana Afwani*, Sri Endang Anjawarni \\ Department of Informatics Engineering, University of Mataram \\ Jl. Majapahit 62, Mataram, Lombok NTB, INDONESIA \\ Email: azmichairani@gmail.com.:[royana, endang]@unram.ac.id
}

*Penulis korespondensi

\begin{abstract}
Dinas Tenaga Kerja dan Transmigrasi Provinsi Nusa Tenggara Barat (Disnakertrans NTB) is one of the government organizations that assists the Governor of West Nusa Tenggara on labour and transmigration issues. IT governance in a company or organization is very necessary to harmonize organizational goals and strategies. With the problems found regarding to the resources both human resources and IT resources at Disnakertrans NTB, the purpose of this study was to determine the capability level of IT governance at Disnakertrans NTB using the COBIT 5 framework by focusing on APO01 subdomains: Manage IT management frameworks, and APO07: Manage human resources. The results of the capability level for as is conditions APO01 were at levels 2 and 3, the APO07 capability level were at levels 1,2 , and 3 . Capability levels for to be conditions of APO01 and APO07 were expected at levels 4 and 5. To increase the current level, some recommendations were provided the Disnakertranss NTB to as consideration by in drafting the policies relating to the APO01 and APO07 processes.
\end{abstract}

Keywords: IT governance, capability level, COBIT 5, APO01, APO07.

\section{PENDAHULUAN}

Dinas Tenaga Kerja dan Transmigrasi Provinsi Nusa Tenggara Barat (Disnakertrans NTB) dibentuk berdasarkan peraturan Gubernur NTB Nomor 21 Tahun 2008 yang sebelumnya terdiri dari 2 Dinas (Dinas Tenaga Kerja dan Dinas Transmigrasi) dan kemudian disatukan agar pelaksanaan program dan kegiatan ketenagakerjaan dan ketransmigrasian menjadi lebih efisien, efektif dan berkualitas [1].

Disnakertrans NTB memiliki dua sistem informasi yaitu website dan SIMDA (sistem informasi manajemen daerah). Dalam Website Disnakertrans NTB, terdapat fitur tambahan yaitu klinik konsultasi yang diperuntukkan kepada user untuk melakukan konsultasi online tentang ketenagakerjaan dan ketransmigrasian, dan fitur pencari kerja yang diperuntukkan kepada user untuk mencari kerja. Sementara itu, SIMDA digunakan untuk mendukung kegiatan operasional keuangan instansi persatu tahun. Namun demikian, berdasarkan wawancara yang dilakukan peneliti kepada pimpinan atau kepala Disnakertrans NTB dan Kepala bagian Program serta admin Teknologi Informasi (TI), terdapat kendala dalam proses pengembangan teknologi informasi, di antaranya karena belum ada bagian khusus yang memegang kendali atas tata kelola TI, kurangnya staf atau pegawai yang mahir dalam bidang TI, serta tugas dan tanggungjawab untuk masing-masing personil tim TI belum teratur sehingga menyebabkan kesusahan dalam menangani terjadinya perubahan atau gangguan pada sistem yang terjadi secara tiba-tiba. Kendala-kendala tersebut dapat menjadi penghambat bagi Disnakertrans NTB untuk meraih tujuannya.

Permasalahan-permasalahan tersebut dapat diidentifkasi secara komprehensif (menyeluruh) yaitu dengan tata kelola menggunakan framework COBIT (Control Objectives for Information and Related Technology) 5. COBIT 5 merupakan audit sistem informasi dan dasar pengendalian yang dibuat oleh Information Systems Audit and Control Association (ISACA). COBIT 5 menyediakan prinsip-prinsip, praktek, serta alat-alat analisa yang telah diterima secara umum untuk meningkatkan kepercayaan dan nilai-nilai sistem informasi.

Tujuan Disnakertrans NTB yaitu melaksanakan program dan kegiatan ketenagakerjaan dan ketransmigrasian yang lebih efisien, efektif dan 
berkualitas, serta menangani permasalahan sumber daya manusia untuk pengelolaan TI yang belum dimiliki. Oleh sebab itu, diperlukan tata kelola TI pada Disnakertrans NTB agar sesuai dengan tujuan dan strateginya.

\section{TINJAUAN PUSTAKA DAN LANDASAN TEORI}

Pada bagian ini akan dijelaskan tinjauan pustaka yang digunakan peneliti dan teori-teori yang digunakan dalam menyelesaikan penelitian ini

\section{A. TINJAUAN PUSTAKA}

Penelitian terdahulu telah dilaksanakan oleh PT Krakatau Steel (Persero) Tbk dan PT. Industri Telekomunikasi Indonesia (INTI). PT Krakatau menggunakan domain EDM04, APO07 dan BAI08 [2] sementara PT. Industri Telekomunikasi Indonesia (INTI) menggunakan Framework Cobit 5 pada Domain Align, Plan, And Organize (APO) dan dilakukan oleh I Ketut Adi Putra Prananta, dkk. [3]. Penelitian tersebut menggunkan Domain APO07 dan APO08. Penelitian selanjutnya dilakukan di PT SIER oleh $M$. Afifuddin dan Hari Ginardi. Penelitian tersebut menggunakan Domain EDM01, EDM02, APO01, APO02, APO03, APO05, APO07, BAI01, dan BAI02 [4].

Berdasarkan latar belakang, dapat disimpulkan bahwa tata kelola TI pada suatu organisasi sangat diperlukan untuk membantu manajemen menyelaraskan proses bisnis dan tujuan organisasi sehingga dapat meningkatkan kinerja dari perusahaan atau organisasi terkait. Maka, dari itu pada penelitian ini penulis melakukan tata kelola TI pada Disnakertrans NTB menggunakan kerangka kerja COBIT 5 dengan fokus domain pada APO01 mengenai pengelolaan kerangka kerja manajemen TI dan APO07 mengenai pengelolaan Sumber Daya Manusia (SDM).

\section{B. LANDASAN TEORI}

Berikut ini akan dijelaskan mengenai beberapa landasan teori yang digunakan dalam penelitian ini:

\section{B.1. Tata Kelola Teknologi Informasi}

Tata kelola TI menyediakan struktur yang menghubungkan proses TI, sumber daya TI dan informasi bagi strategi dan tujuan perusahaan atau instansi. Tata kelola TI menggabungkan best practice dari perencanaan dan pengorganisasian TI, pembangunan dan pengimplementasian, delivery and support, serta memantau kinerja TI untuk memastikan informasi perusahaan atau instansi dan teknologi informasi berhubungan dengan tujuan perusahaan atau instansi $[5][6][7]$.

\section{B.2. COBIT 5}

COBIT 5 menyediakan prinsip-prinsip, praktekpraktek, serta alat-alat analisa yang telah diterima secara umum untuk meningkatkan kepercayaan dan nilai sistemsistem informasi. COBIT 5 dibangun berdasarkan pengembangan dari COBIT 4.1 dengan mengintegrasikan
Value IT dan Risk IT dari ISACA, ITIL, dan standarstandar yang relevan dari ISO [8][9].

\section{B.3. Prinsip - Prinsip COBIT 5}

Secara umum COBIT 5 memilik 5 prinsip dasar seperti pada Gambar 1.

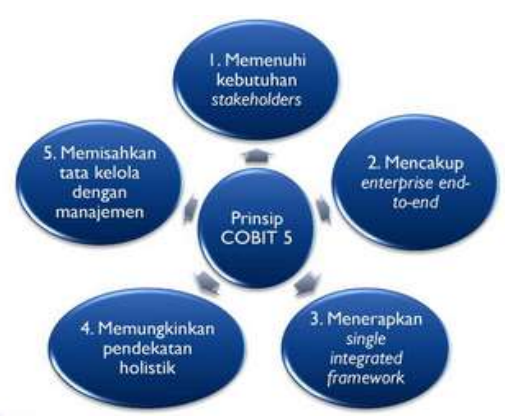

Gambar 1. Prinsip - prinsip dasar COBIT 5 [8].

\section{B.4. COBIT 5 Goals Cascade}

COBIT 5 goals cascade merupakan mekanisme untuk menerjemahkan kebutuhan stakeholder menjadi sasaran perusahaan yang spesifik untuk dapat ditindaklanjuti dan disesuaikan, terutama sasaran yang terkait dengan TI dan tujuan enabler. Langkah - langkah goals cascade dapat dilihat pada Gambar 2.

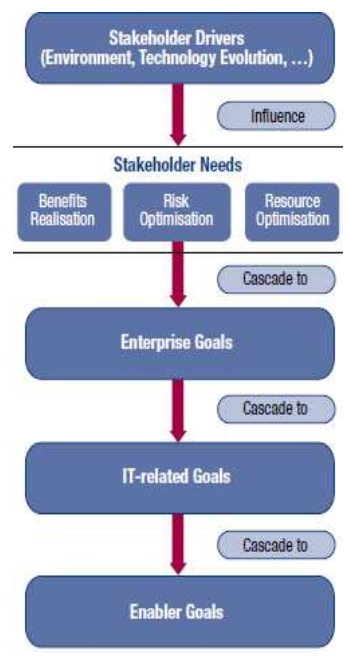

Gambar 2. COBIT 5 goals cascade[8].

\section{B.5. Model Referensi Proses pada COBIT 5}

Proses tata kelola meliputi domain Evaluate, Direct, and Monitor yang terdiri dari 5 proses sedangkan proses manajemen memuat 4 domain yaitu Plan, Build, Run, and Monitor (PBRM) [10].

\section{B.6. Model Kapabilitas Proses COBIT 5}

Pada model kapabilitas proses dilakukan pengukuran performansi di tiap-tiap proses tata kelola atau proses manajemen di mana dilakukan identifikasi dan analisis yang perlu untuk ditingkatkan performansinya [10]. 


\section{B.7. RACI Chart}

RACI (Responsible, Accountable, Consulted and Informed) Chart merupakan grafik paparan peran dan tanggung jawab untuk menyelesaikan suatu proyek proses bisnis organisasi $[10]$.

\section{METODOLOGI PENELITIAN}

Tahapan penelitian ini digambarkan dalam bentuk diagram alir pada Gambar 3.

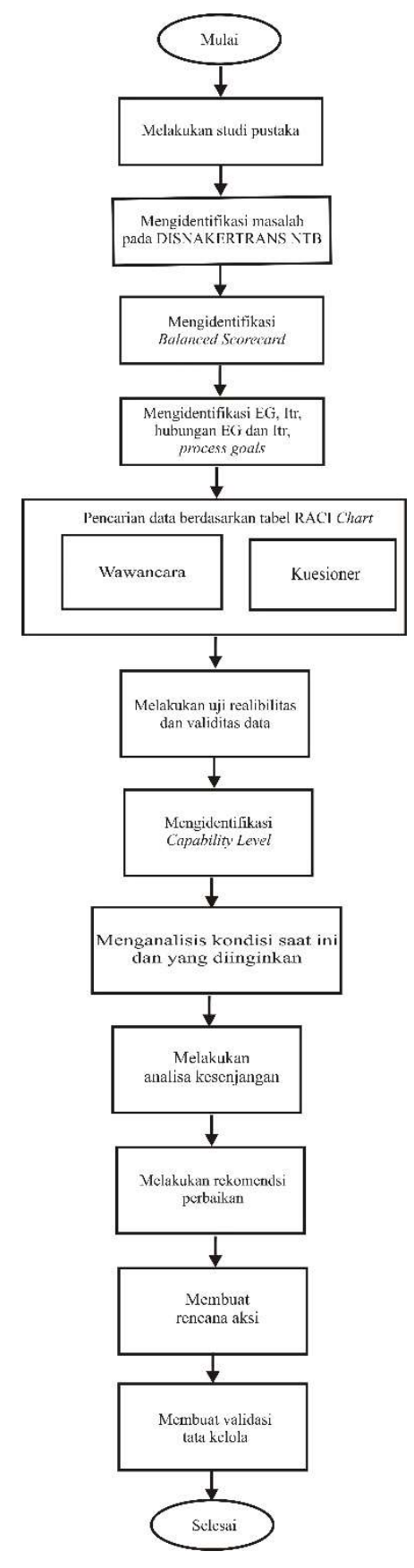

Gambar 3. Flowchart penelitian

\section{A. Melakukan Studi Pustaka}

Melakukan studi pustaka berguna untuk mencari dan mengumpulkan data yang berguna bagi penelitian ini.

\section{B. Mengidentitikasi Masalah}

Dalam menemukan masalah pada penelitian ini, terlebih dahulu dilakukan pengumpulan data menggunakan metode seperti observasi dan wawancara kepada stakeholder yang terkait dengan tata kelola TI pada Disnakertrans NTB.

\section{Mengidentifikasi Balanced Score Card}

Pada tahap ini, diperlukan identifikasi terhadap visi, misi dan strategi Disnakertrans NTB yang dikelompokkan berdasarkan empat perspektif yang dimiliki oleh Balanced Scorecard (BSC) yaitu financial, customer, internal, dan learn and growth.

D. Mengidentifikasi Enterprise Goals, IT - Related Goals, Hubungan Enterprise Goals dan IT - Related Goals serta Process Goals

\section{D.1. Mengidentfikasi Enterprise Goals}

Pada tahap ini, akan didefinisikan enterprise goals sesuai dengan COBIT 5 yang diselaraskan dengan tujuan bisnis dan sasaran Disnakertrans NTB. Dalam COBIT 5, terdapat 17 enterprise goals dan sudah dipetakan sesuai dengan 4 perspektif didalam balanced scoredcard. Sehingga peneliti dapat memilih enterprise goals yang sesuai dengan kebutuhan Disnakertrans NTB.

\section{D.2. Mengidentifikasi IT - Related Goals}

Pada tahap ini dilakukan mapping untuk menentukan IT - Related Goals yang disesuaikan dari enterprise goals yang telah didefinisikan. Kemudian didapatkan keterkaitan antara enterprise goals dengan IT - Related Goals. IT - Related Goals yang terpilih merupakan IT Related Goals yang selaras dengan visi, misi dan startegi Disnakertrans NTB.

\section{D.3. Mengidentifikasi Hubungan Antara Enterprise Goals Dan IT - Related Goals}

Pada tahap ini dilakukan mapping untuk menentukan hubungan antara Entreprise Goals (EG) dan IT - Related Goals (ITr). Kemudian menghasilkan dua keterkaitan yaitu primary (P) yang berarti keterkaitan antara keduanya kuat, dan secondary (S) yang berarti keterkaitan antara keduanya lemah. ITr yang akan digunakan yaitu ITr yang mempunyai nilai $\mathrm{P}$ terhadap EG.

\section{D.4.Mengidentifikasi Process Goals}

Pada tahap ini dilakukan mapping untuk menentukan Process goals yang disesuaikan dari IT - Related Goals. Process goals dicocokkan dengan IT - Related Goals berdasarkan framework COBIT 5 yang sesuai dengan kebutuhan Disnakertrans NTB. Process goals yang diambil (ditulis) pada pemetaan yaitu yang memiliki nilai Primary (P) terhadap IT - Related Goals, sedangkan nilai secondary bisa tidak diambil (ditulis) dalam pemetaan karena sebagai nilai pendukung dari keterkaitan antara keduanya, sehingga didapat process goals yang ditulis paling banyak yaitu APO01 dan APO07. 


\section{E. Pencarian Data Berdasarkan Tabel RACI Chart}

Pencarian data dilakukan dengan dua cara yaitu dengan melakukan wawancara dan pemberian kuisioner berdasarkan hasil RACI Chart dari process goals yang terpilih yaitu APO01 dan APO07.

\section{F. Mengidentifikasi Capability Level}

Pada tahap ini, dilakukan identifikasi capability level terhadap process goals yang telah terpilih. Tujuan dari tahapan ini adalah untuk mengetahui pada level berapa kondisi penerapan teknologi informasi saat ini dan yang diinginkan oleh Disnakertrans NTB

\section{G. Melakukan Analisa Kondisi Saat Ini Dan Yang Diharapkan}

Setelah melakukan perhitungan capability level, maka didapat capability level dari process goals yang dipilih di setiap atribut kematangan. Dari hasil tersebut, selanjutnya dilakukan analisis kondisi saat ini dan kondisi yang akan datang sesuai dengan keadaan Disnakertrans NTB berdasarkan hasil wawancara dan kuisioner sebelumnya.

\section{H. Melakukan Analisa Kesenjangan}

Pada tahap ini dilakukan perhitungan nilai capability level dari hasil kuesioner dan wawancara yang telah dilakukan sebelumnya sehingga ditemukan kesenjangan antara kedua kondisi yaitu kondisi saat ini (as is) dan kondisi diharapkan (to be) pada kedua process goals.

\section{Melakukan Rekomendasi Perbaikan}

Tahapan ini akan memberikan sebuah rekomendasi perbaikan yang diharapkan dapat meningkatkan penerapan TI dari level sebelumnya menjadi level yang lebih baik.

\section{J. Membuat Rencana Aksi}

Untuk meraih tujuan yang diinginkan oleh Disnakertrans maka dibuat rencana aksi. Untuk memudahkan pelaksanaan rencana aksi tersebut diperlukan time table yang dapat menjadi panduan penjadwalan pelaksanaan aksi. Rencana aksi diproyeksikan dapat terlaksana dalam waktu 5 tahun. Rencana aksi dibuat berdasarkan panduan pada COBIT 5.

\section{K. Membuat Validasi Tata Kelola}

Pada tahap ini dilakukan pembuktian elemen tata kelola yang diperoleh dari pendapat para ahli tentang tata kelola berdasarkan visi dan misi Disnakertrans terhadap hasil analisis teknologi informasi. Tujuan dilakukan validasi tata kelola ini untuk memperkuat hasil penelitian dan mengukur sejauh mana kesesuaian hasil yang diperoleh dengan tujuan dan sasaran Disnakertrans.

\section{IV.HASIL DAN PEMBAHASAN}

\section{A. Hasil Kuesioner Process Goals APO01 Dan APO07}

Setelah dilakukan wawancara dan pengisian berdasarkan RACI Roles maka didapatkan hasil kuesioner pada dua process goals yang terpilih yaitu APO01 dan
APO07. Responden pada APO01 sebanyak 41 orang, sedangkan responden pada APO07 sebanyak 29 orang.

\section{A.1. Hasil Perhitungan Nilai IQR}

Dari rekapitulasi kuesioner dilakukan perhitungan nilai IQR yang direpresentasikan ke dalam boxplot diagram seperti yang terlihat pada Gambar 4 dan Gambar 5.

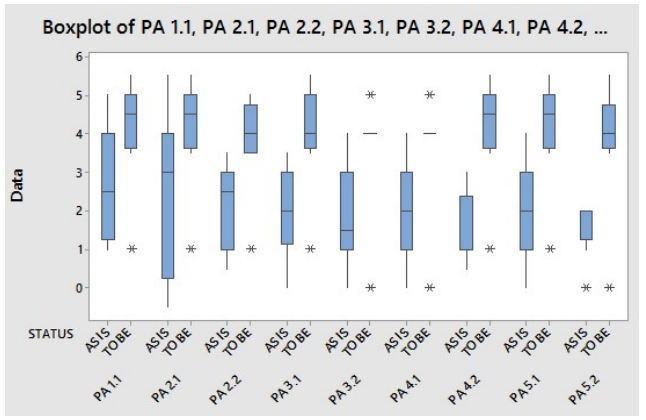

Gambar 4 Boxplot diagram APO01

Pada Gambar 4 dan Gambar 5 dapat dilihat bahwa simbol kotak merepresentasikan Inter Quartile Range (IQR), yaitu kotak pada data as is yang menandakan IQR setiap atribut pada kondisi saat ini, sedangkan kotak pada data to be menandakan IQR setiap atribut pada kondisi diharapkan. Batas terendah merupakan Quartile 1 (Q1) dan batas tertinggi kotak merupakan Quartile 3 (Q3). Garis yang terdapat didalam kotak menandakan data median atau nilai pertengahan dari data yang ada. Sedangkan simbol garis menunjukan batas nilai terkecil ataupun batas nilai terbesar dari data tersebut. Serta simbol bintang $(*)$ menunjukkan nilai outlier (menyimpang).

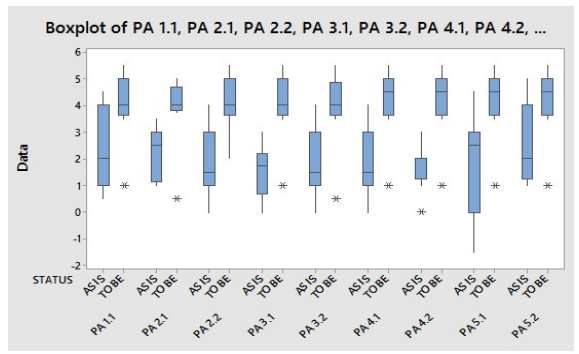

Gambar 5 Boxplot diagram APO07

\section{B. Uji Reliabilitas Dan Validitas Data}

\section{B.1. Uji Reliabilitas Data}

Berikut adalah hasil uji reliabilitas data kedua process goals yaitu APO01 dan APO07 menggunakan Cronbach's Alpha seperti yang terlihat pada Tabel I.

TABEL I HASIL UJI RELIABILITAS DATA APO01 DAN APO07

\begin{tabular}{|c|c|c|c|c|}
\hline NO & $\begin{array}{c}\text { Process } \\
\text { Goals }\end{array}$ & Status & Alpha & Reliabilitas \\
\hline \multirow{2}{*}{1} & \multirow{2}{*}{ APO01 } & As is & 0.8361 & Sangat reliable \\
\cline { 3 - 5 } & \multirow{2}{*}{2} & APO be & 0.9289 & Sangat reliable \\
\cline { 3 - 5 } & APO is & 0.9406 & Sangat reliable \\
\cline { 3 - 5 } & To be & 0.9400 & Sangat reliable \\
\hline
\end{tabular}

\section{B.2. Uji Validitas Data}


Hasil uji reliabilitas data kedua process goals yaitu APO01 dan APO07 menggunakan Korelasi Pearson atau Product Moment ditunjukkan pada Tabel II dan Tabel III.

TABEL II NILAI VALIDITAS APO01

\begin{tabular}{|c|c|l|c|c|c|}
\hline NO & \multirow{2}{*}{ Atribut } & Status & $\begin{array}{c}\text { r- } \\
\text { Hitung }\end{array}$ & $\begin{array}{c}\text { r-Tabel } \\
\mathbf{( N = 4 1 )}\end{array}$ & Validitas* \\
\hline \multirow{2}{*}{1} & \multirow{2}{*}{ PA 1.1 } & As is & 0.684 & 0.308 & Ya \\
\cline { 3 - 6 } & & To be & 0.754 & 0.308 & Ya \\
\hline \multirow{2}{*}{2} & \multirow{2}{*}{ PA 2.1 } & As is & 0.853 & 0.308 & Ya \\
\cline { 3 - 6 } & & To be & 0.754 & 0.308 & Ya \\
\hline \multirow{2}{*}{3} & \multirow{2}{*}{ PA 2.2 } & As is & 0.965 & 0.308 & Ya \\
\cline { 3 - 6 } & & To be & 0.865 & 0.308 & Ya \\
\hline \multirow{2}{*}{4} & \multirow{2}{*}{ PA 3.1 } & As is & 0.640 & 0.308 & Ya \\
\cline { 3 - 6 } & & To be & 0.865 & 0.308 & Ya \\
\hline \multirow{2}{*}{5} & \multirow{2}{*}{ PA 3.2 } & As is & 0.581 & 0.308 & Ya \\
\cline { 3 - 6 } & To be & 0.826 & 0.308 & Ya \\
\hline \multirow{2}{*}{6} & \multirow{2}{*}{ PA 4.1 } & As is & 0.894 & 0.308 & Ya \\
\cline { 3 - 6 } & To be & 0.826 & 0.308 & Ya \\
\hline \multirow{2}{*}{7} & \multirow{2}{*}{ PA 4.2 } & As is & 0.332 & 0.308 & Ya \\
\cline { 3 - 6 } & & To be & 0.683 & 0.308 & Ya \\
\hline \multirow{2}{*}{8} & \multirow{2}{*}{ PA 5.1 } & As is & 0.504 & 0.308 & Ya \\
\cline { 3 - 6 } & To be & 0.800 & 0.308 & Ya \\
\hline 9 & PA 5.2 & As is & 0.736 & 0.308 & Ya \\
\hline
\end{tabular}

*Keterangan : Ya (Valid), Tidak (Tidak Valid)

\section{Menghitung Capability Level}

Setelah diketahui nilai reliabilitas dan validitas data hasil kuesioner, selanjutnya dilakukan perhitungan nilai capability level atau tingkat kematangan yang merupakan tujuan dari dilakukan penelitian ini. Nilai capability level pada kedua process goals dihitung dengan formula:

\section{$\mathbf{X}=\underline{\underline{\text { (level jawaban * jumlah responden) }}}$}

ari persamaan 1 didapatkan nilai capability level masing-masing atribut kedua process goals pada kondisi saat ini maupun kondisi diharapkan seperti yang terlihat pada Tabel IV \& Tabel V.

\section{TABEL III NILAI VALIDITAS APO07}

\begin{tabular}{|c|c|c|c|c|c|}
\hline \multirow{2}{*}{ NO } & \multirow{2}{*}{ Atribut } & Status & $\begin{array}{c}\text { r- } \\
\text { Hitung }\end{array}$ & $\begin{array}{c}\text { r-Tabel } \\
\text { (N=29) }\end{array}$ & Validitas* \\
\hline \multirow{2}{*}{1} & \multirow{2}{*}{ PA 1.1 } & As is & 0.979 & 0.367 & Ya \\
\cline { 3 - 6 } & & To be & 0.881 & 0.367 & Ya \\
\hline \multirow{2}{*}{2} & \multirow{2}{*}{ PA 2.1 } & As is & 0.566 & 0.367 & Ya \\
\cline { 3 - 6 } & & To be & 0.888 & 0.367 & Ya \\
\hline \multirow{2}{*}{3} & \multirow{2}{*}{ PA 2.2 } & As is & 0.979 & 0.367 & Ya \\
\cline { 3 - 6 } & & To be & 0.797 & 0.367 & Ya \\
\hline \multirow{2}{*}{4} & \multirow{2}{*}{ PA 3.1 } & As is & 0.503 & 0.367 & Ya \\
\cline { 3 - 6 } & To be & 0.888 & 0.367 & Ya \\
\hline \multirow{2}{*}{5} & \multirow{2}{*}{ PA 3.2 } & As is & 0.967 & 0.367 & Ya \\
\cline { 3 - 6 } & & To be & 0.888 & 0.367 & Ya \\
\hline \multirow{2}{*}{6} & \multirow{2}{*}{ PA 4.1 } & As is & 0.967 & 0.367 & Ya \\
\cline { 3 - 6 } & To be & 0.768 & 0.367 & Ya \\
\hline \multirow{2}{*}{7} & \multirow{2}{*}{ PA 4.2 } & As is & 0.445 & 0.367 & Ya \\
\cline { 3 - 6 } & To be & 0.768 & 0.367 & Ya \\
\hline \multirow{2}{*}{8} & \multirow{2}{*}{ PA 5.1 } & As is & 0.881 & 0.367 & Ya \\
\cline { 3 - 6 } & To be & 0.790 & 0.367 & Ya \\
\hline \multirow{2}{*}{9} & \multirow{2}{*}{ PA 5.2 } & As is & 0.992 & 0.367 & Ya \\
\cline { 3 - 6 } & To be & 0.768 & 0.367 & Ya \\
\hline
\end{tabular}

*Keterangan : Ya (Valid), Tidak (Tidak Valid)

\begin{tabular}{|c|c|c|c|c|c|}
\hline \multirow[t]{2}{*}{ NO } & \multirow{2}{*}{ ATRIBUT } & \multicolumn{2}{|c|}{$\begin{array}{c}\text { Nilai } \\
\text { Kematangan }\end{array}$} & \multicolumn{2}{|c|}{ Tingkat kematangan } \\
\hline & & as is & to be & as is & to be \\
\hline 1 & PA 1.1 & 3 & 4.634 & 3 & 5 \\
\hline 2 & PA 2.1 & 2.78 & 4.634 & 3 & 5 \\
\hline 3 & PA 2.2 & 1.902 & 4.268 & 2 & 4 \\
\hline 4 & PA 3.1 & 2.268 & 4.268 & 2 & 4 \\
\hline 5 & PA 3.2 & 1.682 & 4.195 & 2 & 4 \\
\hline 6 & PA 4.1 & 2.048 & 4.195 & 2 & 4 \\
\hline 7 & PA 4.2 & 2 & 4.414 & 2 & 4 \\
\hline 8 & PA 5.1 & 1.951 & 4.536 & 2 & 5 \\
\hline 9 & PA 5.2 & 1.902 & 4.268 & 2 & 4 \\
\hline \multicolumn{2}{|c|}{ RATA - RATA } & 2.170 & 4.379 & 2 & 4 \\
\hline
\end{tabular}

TABEL V CAPABILITY LEVEL APO07

\begin{tabular}{|c|c|c|c|c|c|}
\hline \multirow{2}{*}{ NO } & \multirow{2}{*}{ ATRIBUT } & \multicolumn{2}{c|}{$\begin{array}{c}\text { Nilai } \\
\text { Kematangan }\end{array}$} & \multicolumn{2}{c|}{$\begin{array}{c}\text { Tingkat } \\
\text { kematangan }\end{array}$} \\
\cline { 3 - 6 } & & as is & to be & as is & to be \\
\hline 1 & PA 1.1 & 1.413 & 4.275 & 1 & 4 \\
\hline 2 & PA 2.1 & 2.517 & 4.241 & 3 & 4 \\
\hline 3 & PA 2.2 & 2.724 & 4.275 & 3 & 4 \\
\hline 4 & PA 3.1 & 1.724 & 4.241 & 2 & 4 \\
\hline 5 & PA 3.2 & 1.724 & 4.241 & 2 & 4 \\
\hline 6 & PA 4.1 & 1.724 & 4.665 & 2 & 5 \\
\hline 7 & PA 4.2 & 1.827 & 4.665 & 2 & 5 \\
\hline 8 & PA 5.1 & 1.379 & 4.413 & 1 & 4 \\
\hline 9 & PA 5.2 & 2.551 & 4.655 & 3 & 5 \\
\hline \multicolumn{2}{|c|}{ RATA - RATA } & 1.953 & 4.407 & 2 & 4 \\
\hline
\end{tabular}

Dari nilai kematangan dan tingkat kematangan dari kedua process goal yaitu APO01 dan APO07. Tingkat kematangan didapat dari pembulatan ke bawah dan ke atas dari nilai kematangan. Setelah didapat tingkat kematangan, selanjutnya direpresentasikan spiderchart untuk melihat nilai kesenjangan dari masing-masing atribut seperti yang terlihat pada Gambar 6 dan Gambar 7.

\section{SPIDERCHART APO01}

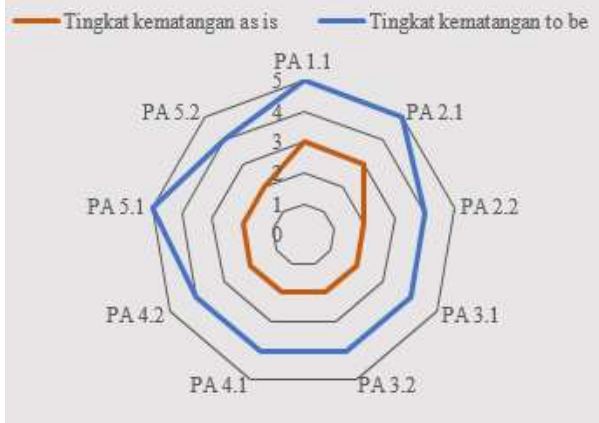

Gambar 6 Spiderchart APO01

Gambar 6 menunjukkan nilai capability level dari masing-masing atribut pada kondisi saat ini (As $I s)$ dan kondisi diharapkan (To Be). Capability level pada kondisi saat ini $(A s I s)$ rata-rata ada di tingkat 2 yaitu managed kecuali pada atribut pada PA 1.1 dan PA 2.1 yang berada di tingkat 3 yaitu established. Sementara itu, pada kondisi diharapkan, rata-rata tingkat kematangannya ada di tingkat 4 yaitu predictable, kecuali pada atribut PA 1.1, PA 2.1 dan PA 5.1 yang ada di tingkat 5 yaitu optimizing.

TABEL IV CAPABILITY LEVEL APO01 


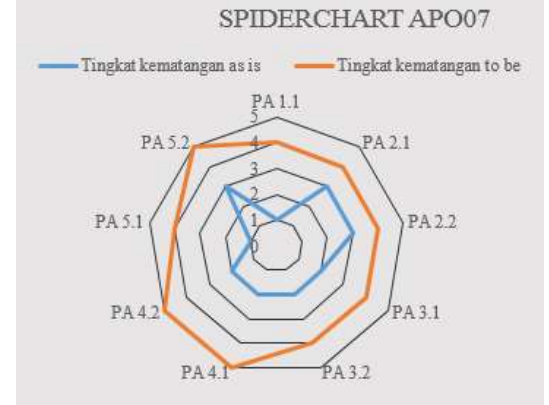

Gambar 7 Spiderchart APO07

Pada Gambar 7, Capability level pada kondisi saat ini (As Is) rata-rata berada di level/tingkat 2 yaitu managed kecuali pada atribut pada PA 1.1 dan PA 5.1 yang berada di tingkat 1 yaitu performed, serta pada atribut PA 2.1, PA 2.2 dan PA 5.2 berada di tingkat 3 yaitu established. Sementara itu, pada kondisi diharapkan rata-rata tingkat kematangannya berada di tingkat 4 yaitu predictable, kecuali pada atribut PA 4.1, PA 4.2 dan PA 5.2 yang berada di tingkat 5 yaitu optimizing.

\section{Analisa Kondisi Saat Ini Dan Diharapkan}

\section{D.1. Analisa kondisi saat ini}

Pada APO01 dengan atribut PA 1.1 (proses kinerja) ada di tingkat 3 yang berarti bahwa proses kinerja yang terdapat di Disnakertrans NTB dalam mengelola Kerangka Kerja Manajemen TI (selanjutnya disingkat KKMTI) telah diimplementasikan sesuai dengan tujuan dari Disnakertrans NTB, tetapi belum dapat diimplementasikan dengan baik. Di sisilain, pada APO07 berada di tingkat 1 yang berarti bahwa proses kinerja yang dilakukan oleh Disnakertrans NTB untuk mengelola Sumber Daya Manusia (SDM) sudah terdapat kesadaran akan pentingnya keterampilan dan kompetensi dari staf untuk meningkatkan kinerja instansi, namun belum terdapat pendekatan yang menyeluruh.

Pada APO01 dan APO07, dengan atribut PA 2.1 (manajemen kinerja) berada di tingkat 3 berarti bahwa manajemen kinerja untuk mengelola KKMTI dan mengelola sumber daya manusia pada Disnakertrans NTB dijalankan sesuai dengan tanggung jawab dan otoritas untuk menjalankan proses-proses telah dikomunikasikan tetapi belum konsisten.

Pada APO01, atribut PA 2.2 (manajemen hasil kinerja) berada di tingkat 2 yang berarti bahwa hasil kinerja untuk mengelola KKMTI sudah mencapai target dengan terpenuhinya persyaratan-persyaratan yang telah disetujui tetapi belum didokumentasikan. Sementara itu, APO07 berada di tingkat 3 yang berarti bahwa manajemen hasil kinerja yang dilakukan oleh Disnakertrans NTB untuk mengelola SDM telah berhasil mencapai target untuk mendapatkan staf yang kompeten di bidang TI, didokumentasikan, dan dikontrol.

Pada APO01 dan APO07 dengan atribut PA 3.1 (proses definisi) berada di tingkat 2 berarti bahwa pendefinisian standar dan kebijakan yang terdapat pada Disnakertrans NTB untuk mengelola KKMTI dan mengelola SDM sudah dijalankan berdasarkan hukum dan panduan-panduan yang jelas, akan tetapi belum terdapat pendekatan yang menyeluruh.

Pada APO01 dan APO07 dengan atribut PA 3.2 (proses penyebaran) ada di tingkat 2 yang berarti bahwa proses penyebaran atau hasil yang dicapai oleh Disnakertrans NTB untuk mengelola KKMTI dan mengelola SDM sudah mulai diterapkan menggunakan proses standar yang sesuai dan telah didokumentasikan.

Pada APO01 dan APO07, dengan atribut PA 4.1 (proses pengukuran) berada di tingkat 2 berarti bahwa proses pengukuran dan pengawasan yang dilakukan Disnakertrans NTB untuk mengelola KKMTI dan mengelola SDM telah dilakukan tetapi tidak memberikan solusi karena tidak ada koordinasi yang jelas.

Pada APO01 dan APO07, dengan atribut PA 4.2 (proses kontrol) berada di tingkat 2 berarti bahwa proses pengontrolan yang dilakukan Disnakertrans NTB untuk mengelola KKMTI dan mengelola SDM telah dilakukan dengan pencapain yang dihasilkan di atas 50\% dan disertai dengan dokumentasi yang jelas.

Pada APO01, dengan atribut PA 5.1 (proses inovasi) berada di tingkat 2 berarti bahwa proses inovasi dilakukan oleh Disnakertrans NTB untuk mengelola KKMTI yaitu dengan mendefinisikan sasaran perbaikan untuk mendukung proses pengelolaan KKMTI yang relevan, tetapi berdasarkan ide individu, sedangkan APO07 berada di tingkat 1 yang berarti bahwa proses inovasi yang dilakukan Disnakertrans NTB dalam mengelola SDM dengan mendefinisikan sasaran proses perbaikan untuk mendukung ketersediaan SDM yang relevan mulai dianggap penting.

Pada APO01, dengan atribut PA 5.2 (proses optimisasi) berada di tingkat 2 berarti bahwa dampak dari proses optimisasi dilakukan oleh Disnakertrans NTB untuk mengelola KKMTI memberikan dampak dan dapat dioptimalkan dengan pendefinisian struktur organisasi yang ada, sedangkan APO07 berada di tingkat 3 yang berarti bahwa proses optimisasi dalam mengelola SDM berdampak pada perubahan yang diusulkan dan dinilai berdasarkan sasaran pengelolaan SDM tetapi tidak berdasarkan proses standar.

\section{D.2. Analisa Kondisi Diharapkan}

Pada APO01, dengan atribut PA 1.1 (proses kinerja) berada di tingkat 5 berarti bahwa proses kinerja pada Disnakertrans NTB menginginkan penerapan dan pengeloaan sistem manajemen TI yang telah diimplementasikan dipertahankan dan dikembangkan sesuai dengan tujuan dari Disnakertrans NTB. Sementara itu, APO07 menginginkan berada di tingkat 4 yang berarti bahwa proses kinerja yang dilakukan Disnakertrans NTB dalam mengelola SDM menyadari pentingnya perekrutan staf yang sesuai dengan keterampilan dan kompetensinya agar instansi dapat berkembang dengan baik dan sesuai dengan tujuan dari DisnakertransT NTB. 
Pada APO01, dengan atribut PA 2.1 (manajemen kinerja) berada di tingkat 5 berarti bahwa Disnakertrans NTB menginginkan terkelolanya manajemen kinerja dalam mengelola KKMTI sebagai sarana penghubung antara pihak-pihak yang terlibat untuk memastikan komunikasi yang efektif serta penunjukan penanggungjawab yang jelas. Sementara itu, APO07 menginginkan berada di tingkat 4 yang berarti bahwa manajemen kinerja yang dilakukan Disnakertrans NTB dalam mengelola SDM sudah teridentifikasi, tersedia, telah dialokasikan serta digunakan untuk mendapatkan staf yang kompeten dibidang TI.

Pada APO01 dan APO07, dengan atribut PA 2.2 (manajemen hasil kinerja) menginginkan berada di tingkat 4 berarti bahwa manajemen hasil kinerja pada Disnakertrans NTB menginginkan target yang dicapai untuk mengelola KKMTI dan mengelola SDM diimplementasikan dan dioperasikan sesuai kebutuhan instansi.

Pada APO01 dan APO07, dengan atribut PA 3.1 (proses definisi) menginginkan berada di tingkat 4, berarti bahwa proses pendefinisian kebijakan dan standar yang dilakukan Disnakertrans NTB untuk mengelola KKMTI dan mengelola SDM, menerapkan penilaian terhadap kebijakan dan standar mengenai infrastruktur dan lingkungan kerja sesuai dengan tujuan dari Disnakertrans NTB.

Pada APO01 dan APO07, dengan atribut PA 3.2 (proses penyebaran) menginginkan berada di tingkat 4 berarti bahwa proses penyebaran atau hasil yang dicapai, Disnakertrans NTB dalam mengelola KKMTI dan mengelola SDM untuk meningkatkan kinerja staf atau pegawai telah dioperasikan dan diimplementasikan sesuai dengan tujuan dari instansi.

Pada APO01, dengan atribut PA 4.1 (proses pengukuran) berada di tingkat 4 berarti bahwa proses pengawasan dan pengukuran dalam mengelola kerangka kerja manajemen TI, Disnakertrans NTB menginginkan sebagai topik yang dianggap penting dan dilakukan secara rutin, konsisten, terjadwal dan pendokumentasian secara berkelanjutan, sedangkan pada APO07 menginginkan berada di tingkat 5 yang berarti bahwa proses pengawasan dan pengukuran yang dilakukan Disnakertrans NTB dalam mengelola SDM dilakukan sebaik mungkin untuk mendapatkan tujuan yang dicapai, dengan adanya pemahaman pihak-pihak untuk meningkatkan kinerja masing-masing dan pengembangan yang berkelanjutan.

Pada APO01, dengan atribut PA 4.2 (proses kontrol) menginginkan berada di tingkat 4 berarti proses pengontrolan yang diinginkan Disnakertrans NTB dalam mengelola KKMTI telah tercapai, diimplementasikan, dan dijalankan sesuai kebutuhan instansi, sedangkan APO07 menginginkan berada di tingkat 5 yang berarti bahwa proses pengontrolan yang dilakukan Disnakertrans NTB dalam mengelola SDM dievaluasi secara rutin dan dikembangkan sesuai kebutuhan berdasarkan SOP yang ada.
Pada APO01, dengan atribut PA 5.1 (proses inovasi) berada di tingkat 5 berarti proses inovasi yang diinginkan oleh Disnakertrans NTB dilakukan dengan cara membuat strategi implementasi untuk meraih sasaran perbaikan dalam mengelola KKMTI, sedangkan APO07 menginginkan berada di tingkat 4 yang berarti bahwa proses inovasi yang dilakukan Disnakertrans NTB dalam mengelola SDM dilakukan dengan cara melihat peluang perbaikan dan inovasi yang diperoleh dari teknologi baru dan konsep proses yamg teridentifikasi untuk mendukung proses pengelolaan SDM.

Pada APO01, dengan atribut PA 5.2 (proses optimisasi) berada di tingkat 4 berarti proses optimisasi yang diinginkan oleh Disnakertrans NTB yaitu dengan mengimplementasi perubahan yang telah disepakati dalam mengelola KKMTI untuk memastikan bahwa segala gangguan terhadap kinerja proses dapat dipahami dan diatasi, sedangkan APO07 menginginkan berada di tingkat 4 yang berarti bahwa proses optimisasi yang dilakukan Disnakertrans NTB dalam mengelola SDM dilakukan berdasarkan kinerja dari pengelolaan SDM yang sebenarnya dan efektivitas proses perubahan dievaluasi terhadap tujuan dari instansi.

\section{E. Analisis Kesenjangan}

Setelah menentukan capability level tata kelola teknologi informasi untuk kondisi saat ini dan kondisi diharapkan didapat nilai tingkat kesenjangan. pada APO01 pada atribut PA 1.1, PA 2.1,PA 2.2, PA 3.1, PA 3.2, PA 4.1, PA 4.2, dan PA 5.2 adalah 2, sedangkan pada atribut PA 5.1 adalah 3. Untuk nilai kesenjangan pada APO07, pada atribut PA 1.1, PA 4.1, PA 4.2 dan PA 5.1 adalah 3, sedangkan pada atribut PA 3.1, PA 3.2 dan PA 5.2 adalah 2, serta pada atribut PA 2.1 dan PA 2.2 adalah 1.

\section{F. Rekomendasi Perbaikan}

Berikut merupakan rekomendasi perbaikan berdasarkan atau disesuaikan dengan tingkat atau level yang ingin dituju oleh Disnakertrans NTB.

\section{F.1. Rekomendasi tindakan untuk meraih capability level 3 pada APOO1}

TABEL VI REKOMENDASI TINDAKAN UNTUK MERAIH CAPABILITY LEVEL 3 PADA APO01

\begin{tabular}{|c|c|}
\hline Atribut & Tindakan perbaikan \\
\hline $\begin{array}{c}\text { PA } 2.2 \\
\text { (work } \\
\text { product } \\
\text { manage- } \\
\text { ment) }\end{array}$ & $\begin{array}{l}\text { - Melakukan perencanaan dan pengorganisasian } \\
\text { kembali terhadap persediaan sumber daya dan } \\
\text { layanan TI yang ada. } \\
\text { - Mengidentifikasi dan merumuskan SOP yang } \\
\text { dapat mengukur ketersediaan sumber daya dan } \\
\text { layanan TI pada Disnakertrans NTB. }\end{array}$ \\
\hline $\begin{array}{l}\text { PA } 3.1 \\
\text { (process } \\
\text { definiti- } \\
\text { on) }\end{array}$ & $\begin{array}{l}\text { - Mendefinisikan kebijakan dan standar serta } \\
\text { panduan yang digunakan untuk melakukan proses } \\
\text { mengelola KKMTIpada Disnakertrans NTB agar } \\
\text { dapat berjalan dengan baik dan sesuai dengan } \\
\text { tujuan dari Disnakertrans NTB } \\
\text { - Melakukan pendokumentasian terhadap kebijakan } \\
\text { dan standar dalam melakukan pengelolaan } \\
\text { KKMTI. }\end{array}$ \\
\hline PA 2.2 & - Mengkomunikasikan secara formal dan terstruktur \\
\hline
\end{tabular}




\begin{tabular}{|c|c|}
\hline & \\
\hline $\begin{array}{l}\text { (work } \\
\text { product } \\
\text { manage- }\end{array}$ & $\begin{array}{l}\text { dengan seluruh staff pada Disnakertrans NTB } \\
\text { tentang hal untuk meningkatkan kinerja staf dalam } \\
\text { mencapai tujuan dari Disnakertrans NTB. }\end{array}$ \\
\hline $\begin{array}{l}\text { PA } 3.1 \\
\text { (process } \\
\text { definiti- } \\
\text { on) }\end{array}$ & $\begin{array}{l}\text { - Mengidentifikasi kebutuhan informasi untuk } \\
\text { melakukan pengukuran terhadap pentingnya TI } \\
\text { dalam rangka mendukung tercapainya tujuan } \\
\text { Disnakertrans NTB. } \\
\text { - Mendokumentasikan data dan informasi dari } \\
\text { pelaksanaan pengukuran terhadap pentingnya TI } \\
\text { yang tersedia untuk mendukung tujuan } \\
\text { Disnakertrans NTB. }\end{array}$ \\
\hline $\begin{array}{l}\text { PA } 3.2 \\
\text { (process } \\
\text { deploy- } \\
\text { ment) }\end{array}$ & $\begin{array}{l}\text { - Menentukan teknik analisis dan kontrol untuk } \\
\text { pengukuran kuantitatif terhadap kinerja staf dalam } \\
\text { bidang TI yang relevan dengan tujuan } \\
\text { Disnakertrans NTB. }\end{array}$ \\
\hline $\begin{array}{l}\text { PA } 4.1 \\
\text { (process } \\
\text { measure- } \\
\text { ment) }\end{array}$ & $\begin{array}{l}\text { - Mengidentifikasikan sasaran dalam peningkatan } \\
\text { kinerja staf dalam bidang TI untuk mendukung } \\
\text { tujuan Disnakertrans NTB. } \\
\text { - Mengevaluasi sasaran yang dicapai untuk } \\
\text { meningkatkan kinerja staf dalam bidang TI pada } \\
\text { Disnakertrans NTB. }\end{array}$ \\
\hline $\begin{array}{l}\text { PA } 4.2 \\
\text { (process } \\
\text { control) }\end{array}$ & $\begin{array}{l}\text { - Menentukan dampak yang dari perubahan } \\
\text { kebijakan dalam bidang TI agar relevan (sesuai) } \\
\text { dengan tujuan Disnakertrans NTB dan selaras } \\
\text { dengan perkembangan teknologi. }\end{array}$ \\
\hline
\end{tabular}

\section{F.2. Rekomendasi tindakan untuk meraih capability level 4 pada APOO1}

TABEL VII REKOMENDASI TINDAKAN UNTUK MERAIH CAPABILITY LEVEL 4 PADA APO01

\begin{tabular}{|c|c|}
\hline Atribut & Tindakan perbaikan \\
\hline $\begin{array}{l}\text { PA } 1.1 \\
\text { (process } \\
\text { perfor- } \\
\text { mance) }\end{array}$ & $\begin{array}{l}\text { - Mengimplementasikan perkembangan teknologi } \\
\text { pada DISNAKERTANS NTB sesuai dengan SOP } \\
\text { yang terdapat pada Disnakertrans NTB untuk } \\
\text { kebutuhan yang akan datang. } \\
\text { - Melakukan penilaian terhadap resiko dan potensi } \\
\text { dalam mengimplementasikan teknologi untuk } \\
\text { mengetahui kekuatan, ancaman, dan masalah } \\
\text { perkembangan teknologi tersebut. }\end{array}$ \\
\hline $\begin{array}{l}\text { PA } 2.1 \\
\text { (perfor- } \\
\text { mance } \\
\text { manage- } \\
\text { ment) }\end{array}$ & $\begin{array}{l}\text { - Melakukan komunikasi tentang pengelolaan } \\
\text { teknologi informasi dengan pihak yang terkait, } \\
\text { dengan tujuan menghasilkan komunikasi yang } \\
\text { efektif dan konsisten. } \\
\text { - Menjalankan hasil komunikasi yang telah } \\
\text { disepakati sesuai dengan kebutuhan Disnakertrans } \\
\text { NTB. } \\
\text { - Melakukan evaluasi terhadap hasil komunikasi } \\
\text { yang dihasilkan. }\end{array}$ \\
\hline $\begin{array}{l}\text { PA } 2.2 \\
\text { (work } \\
\text { product } \\
\text { manage- } \\
\text { ment) }\end{array}$ & $\begin{array}{l}\text { - Mengimplementasikan hasil dari setiap kegiatan } \\
\text { yang mendukung proses pengelolaan teknologi } \\
\text { informasi pada Disnakertrans NTB agar dapat } \\
\text { terdokumentasi, dan terkontrol dengan baik. } \\
\text { - Melakukan pengembangan teknologi informasi } \\
\text { untuk mendukung ketersediaan sumber daya TI. }\end{array}$ \\
\hline $\begin{array}{l}\text { PA } 3.1 \\
\text { (process } \\
\text { definiti- } \\
\text { on) }\end{array}$ & $\begin{array}{l}\text { - Mengimplementasikan kebijakan dan standar serta } \\
\text { panduan yang digunakan untuk meningkatkan } \\
\text { kinerja staf untuk mengelola teknologi informasi } \\
\text { yang terdapat pada Disnakertrans NTB. } \\
\text { - Melakukan penilaian terhadap standar dan } \\
\text { kebijakan serta panduan yang digunakan untuk } \\
\text { meningkatkan kinerja staf dalam pengelolaan } \\
\text { teknologi informasi. }\end{array}$ \\
\hline $\begin{array}{c}\text { PA } 3.2 \\
\text { (process } \\
\text { deploy- } \\
\text { ment) }\end{array}$ & $\begin{array}{l}\text { - Melakukan pengumpulan dan analisa data } \\
\text { pengelolaan teknologi informasi untuk menilai } \\
\text { kinerja, kesesuaian, dan efektifitas proses, serta } \\
\text { untuk mengetahui, potensi peningkatan kualitas } \\
\text { proses secara terus menerus dalam proses }\end{array}$ \\
\hline
\end{tabular}

\begin{tabular}{|c|c|}
\hline Atribut & Tindakan perbaikan \\
\hline & pnegelolaan kerangka kerja manajemen TI. \\
\hline $\begin{array}{l}\text { PA } 1.1 \\
\text { (process } \\
\text { perfor- } \\
\text { mance) }\end{array}$ & $\begin{array}{l}\text { - Menentukan unit yang akan diukur dalam proses } \\
\text { pengelolaan dan perkembangan teknologi } \\
\text { informasi yang disesuaikan dengan model dan } \\
\text { frekuensi pengukuran pada proses pengelolaan } \\
\text { KKMTIuntuk memberikan penilaian kinerja secara } \\
\text { kuantitatif terhadap staf dibidang TI. }\end{array}$ \\
\hline $\begin{array}{l}\text { PA } 2.1 \\
\text { (perfor- } \\
\text { mance } \\
\text { manage- } \\
\text { ment })\end{array}$ & $\begin{array}{l}\text { - Membuat rencana strategis terkait dengan TI untuk } \\
\text { memudahkan dalam pengambilan keputusan yang } \\
\text { optimal dalam bidang TI khususnya proses } \\
\text { pengelolaan kerangka kerja manajemen TI. } \\
\text { - Membuat penilaian terhadap ketersediaan sumber } \\
\text { daya dan layanan TI dalam pelaksanaan proses } \\
\text { pengelolaan kerangka kerja manajemen TI. }\end{array}$ \\
\hline $\begin{array}{l}\text { PA } 2.2 \\
\text { (work } \\
\text { product } \\
\text { manage- } \\
\text { ment) }\end{array}$ & $\begin{array}{l}\text { - Melakukan analisa data yang sesuai untuk } \\
\text { mengidentifikasi potensi penggunaan metode best } \\
\text { practice maupun inovasi terhadap metode } \\
\text { pelaksanaan proses pengelolaan kerangka kerja } \\
\text { manajemen TI. } \\
\text { - Mengidentifikasi potensi peningkatan proses } \\
\text { pengelolaan KKMTIdari kemunculan teknologi } \\
\text { baru tanpa mengganggu kinerja staff dalam } \\
\text { instansi }\end{array}$ \\
\hline $\begin{array}{l}\text { PA } 3.1 \\
\text { (process } \\
\text { definiti- } \\
\text { on) }\end{array}$ & $\begin{array}{l}\text { - Menjalankan peraturan }- \text { peraturan terhadap } \\
\text { penerapan seluruh perubahan yang disetujui. }\end{array}$ \\
\hline
\end{tabular}

F.3. Rekomendasi tindakan untuk meraih capability level 5 pada APOO1

\section{TABEL VIII REKOMENDASI TINDAKAN UNTUK MERAIH} CAPABILITY LEVEL 5 PADA APO01

\begin{tabular}{|c|c|}
\hline Atribut & Tindakan perbaikan \\
\hline $\begin{array}{l}\text { PA } 1.1 \\
\text { (process } \\
\text { perfor- } \\
\text { mance) }\end{array}$ & $\begin{array}{l}\text { - Melakukan pengembangan dan pemeliharaan } \\
\text { secara rutin mengenai ketersediaan sumber daya TI } \\
\text { terhadap proses pengelolaan KKMTIagar tujuan } \\
\text { dari DISNAKERTRAN NTB dapat berjalan } \\
\text { dengan efektif dan efisien. } \\
\text { - Melakukan pemantauan, penilaian dan evaluasi } \\
\text { terhadap SOP yang disetujui untuk proses } \\
\text { pengelolaan kerangka kerja manajemen TI. }\end{array}$ \\
\hline $\begin{array}{l}\text { PA } 2.1 \\
\text { (perfor- } \\
\text { mance } \\
\text { manage- } \\
\text { ment) }\end{array}$ & $\begin{array}{l}\text { - Memonitoring dan mengevaluasi sumber daya TI } \\
\text { untuk membantu manajemen kinerja yang } \\
\text { dibutuhkan untuk proses pengelolaan kerangka } \\
\text { kerja manajemen TI. }\end{array}$ \\
\hline $\begin{array}{l}\text { PA } 5.1 \\
\text { (process } \\
\text { innova- } \\
\text { tion) }\end{array}$ & $\begin{array}{l}\text { - Merencanakan strategi implementasi dari usulan } \\
\text { perubahan teknologi informasi untuk mewujudkan } \\
\text { sasaran peningkatan proses pengelolaan KKMTI }\end{array}$ \\
\hline
\end{tabular}

\section{F.4. Rekomendasi tindakan untuk meraih capability level 2 pada APO07}

\section{TABEL IX REKOMENDASI TINDAKAN UNTUK MERAIH CAPABILITY LEVEL 2 PADA APO07}

\begin{tabular}{|c|l|}
\hline Atribut & \multicolumn{3}{|c|}{ Tindakan perbaikan } \\
\hline $\begin{array}{l}\text { PA 1.1 } \\
\text { process } \\
\text { perfor- } \\
\text { mance) }\end{array}$ & $\begin{array}{l}\text { Mengidentifikasikan keterampilan dan kompetensi } \\
\text { dasar staf TI untuk meraih tujuan Dari }\end{array}$ \\
\hline & Disnakertrans NTB. \\
PA 5.1 & Mengidentifikasi sasaran peningkatan proses \\
process & $\begin{array}{l}\text { pelatihan - pelatihan yang diselenggarakan secara } \\
\text { formal seperti BIMTEK } \text { - }\end{array}$ \\
tion) & $\begin{array}{l}\text { yang diadakan oleh pihak - pihak yang terkait } \\
\text { untuk mendukung tujuan dari Disnakertrans NTB. }\end{array}$ \\
\hline
\end{tabular}




\section{F.5. Rekomendasi tindakan untuk meraih capability level 3 pada APO07}

\section{TABEL X REKOMENDASI TINDAKAN UNTUK MERAIH CAPABILITY LEVEL 3 PADA APO07}

\begin{tabular}{|c|c|}
\hline & \\
\hline $\begin{array}{l}\text { PA } 1.1 \\
\text { (process } \\
\text { perfor- } \\
\text { mance) }\end{array}$ & $\begin{array}{l}\text { - Melakukan perkrutan staf TI untuk mendukung } \\
\text { kinerja dalam pengelolaan SDM. } \\
\text { - Merencanakan dan melakukan pelatihan terhadap } \\
\text { aplikasi yang digunakan oleh Disnakertrans NTB } \\
\text { kepada staf TI baru }\end{array}$ \\
\hline $\begin{array}{l}\text { PA } 3.1 \\
\text { (process } \\
\text { definiti- } \\
\text { on) }\end{array}$ & $\begin{array}{l}\text { - Mendefinisikan kebijakan dan standar yang } \\
\text { terdapat dalam proses pengelolaan SDM dengan } \\
\text { mengidentifikasi elemen-elemen dasar, } \\
\text { menyediakan panduan dan prosedur yang } \\
\text { mendukung untuk meningkatkan keterampilan dan } \\
\text { kemampuan staf TI. }\end{array}$ \\
\hline & $\begin{array}{l}\text { at SOP yang baku untuk mengelola SDM } \\
\text { etiap unit kerja yang ditetapkan secara } \\
\text { dan dilaksanakan dengan baik dan tepat }\end{array}$ \\
\hline $\begin{array}{l}\text { PA } 4.1 \\
\text { (process } \\
\text { measure- } \\
\text { ment })\end{array}$ & $\begin{array}{l}\text { - Mengkomunikasikan dengan seluruh staf pada } \\
\text { Disnakertrans NTB untuk mengadakan sosialisasai } \\
\text { mengenai pentingnya mengelola SDM dalam } \\
\text { bidang TI. } \\
\text { - Melakukan pengukuran dan evaluasi pada setiap } \\
\text { kemajuan kinerja dalam mengelola SDM dalam } \\
\text { bidang TI. }\end{array}$ \\
\hline & $\begin{array}{l}\text { - Melakukan penilaian dan evaluasi secara rutin } \\
\text { terhadap perkembangan keterampilan dan } \\
\text { kompetensi staf TI. }\end{array}$ \\
\hline $\begin{array}{l}\text { PA } 5.2 \\
\text { (process } \\
\text { optimizat }\end{array}$ & $\begin{array}{l}\text { - Menetapkan pengaturan sumber daya yang } \\
\text { fleksibel untuk mendukung perubahan kebutuhan } \\
\text { bisnis. }\end{array}$ \\
\hline
\end{tabular}

F.6. Rekomendasi tindakan untuk meraih capability level 4 pada $\mathrm{APO07}$

\section{TABEL XI REKOMENDASI TINDAKAN UNTUK MERAIH CAPABILITY LEVEL 4 PADA APO07}

\begin{tabular}{|c|c|}
\hline Atribut & $\begin{array}{l}\text { Tindakan perbaikan } \\
\end{array}$ \\
\hline $\begin{array}{l}\text { PA } 1.1 \\
\text { (process } \\
\text { perfor- } \\
\text { mance) }\end{array}$ & $\begin{array}{l}\text { - Merencanakan pengembangan karir secara formal } \\
\text { dan professional untuk mendorong perkembangan } \\
\text { kompetensi staff TI }\end{array}$ \\
\hline $\begin{array}{l}\text { PA } 2.1 \\
\text { (perfor- } \\
\text { mance } \\
\text { manage- } \\
\text { ment) }\end{array}$ & $\begin{array}{l}\text { - Memberikan pelatihan terhadap staf TI untuk } \\
\text { meningkatkan pengetahuan, keterampilan, dan } \\
\text { kemampuan yang diperlukan dalam mengelola } \\
\text { SDM dalam bidang TI sesuai dengan kebutuhan } \\
\text { dan keinginan yang diperlukan Disnakertrans } \\
\text { NTB. }\end{array}$ \\
\hline $\begin{array}{l}\text { PA } 2.2 \\
(\text { work } \\
\text { product } \\
\text { manage- } \\
\text { ment })\end{array}$ & $\begin{array}{l}\text { - } \text { Mengembangkan program pelatihan berdasarkan } \\
\text { persyaratan yang dibutuhkan untuk } \\
\text { mengembangkan keterampilan dan kemampuan } \\
\text { staff TI dalam mengelola SDM dalam bidang TI. }\end{array}$ \\
\hline $\begin{array}{l}\text { PA } 3.1 \\
\text { (process } \\
\text { definition } \\
\quad \text { ) }\end{array}$ & $\begin{array}{l}\text { - Mendefinisikan kebijakan dan standar secara } \\
\text { regular dilingkungan instansi yang diperlukan } \\
\text { dalam mengelola SDM yang memadai untuk } \\
\text { mendukung tujuan dan sasaran Disnakertrans } \\
\text { NTB. }\end{array}$ \\
\hline $\begin{array}{l}\text { PA } 3.2 \\
\text { (process } \\
\text { deploy- } \\
\text { ment) }\end{array}$ & $\begin{array}{l}\text { - Mengidentifikasi kesenjangan antara keterampilan } \\
\text { yang dibutuhkan dan tersedia proses pengelolaan } \\
\text { SDM. }\end{array}$ \\
\hline $\begin{array}{l}\text { PA } 4.1 \\
\text { (process } \\
\text { measure- } \\
\text { ment) }\end{array}$ & $\begin{array}{l}\text { - Melakukan pengukuran efisiensi dan } \\
\text { efektivitas proses pengelolaan SDM yang } \\
\text { dibutuhkan oleh Disnakertrans NTB. }\end{array}$ \\
\hline
\end{tabular}

\begin{tabular}{|c|c|}
\hline Atribut & Tindakan perbaikan \\
\hline $\begin{array}{l}\text { PA } 4.2 \\
\text { (process } \\
\text { control) }\end{array}$ & $\begin{array}{l}\text { - Melakukan evaluasi terhadap pengetahuan tiap staf } \\
\text { TI agar hal yang dikerjakan sesuai stardar prosedur } \\
\text { dan selaras dengan tujuan Disnakertrans NTB. }\end{array}$ \\
\hline $\begin{array}{l}\text { PA } 5.1 \\
\text { (process } \\
\text { innova- } \\
\text { tion) }\end{array}$ & $\begin{array}{l}\text { - Menetapkan standar dan kebijakan proses } \\
\text { pengelolaan SDM, misalnya kriteria yang } \\
\text { dibutuhkan seperti kemampuan, keterampilan dan } \\
\text { keahlian. }\end{array}$ \\
\hline $\begin{array}{l}\text { PA } 5.2 \\
\text { (process } \\
\text { optimiza- } \\
\text { tion) }\end{array}$ & $\begin{array}{l}\text { - Mengidentifikasi kekurangan dan memberikan } \\
\text { masukan terhadap permintaan SDM saat ini dan } \\
\text { akan datang untuk mendukung pencapaian tujuan } \\
\text { Disnakertrans NTB. }\end{array}$ \\
\hline
\end{tabular}

\section{F.7. Rekomendasi tindakan untuk meraih capability level 5 pada APOO7}

\section{TABEL XII REKOMENDASI TINDAKAN UNTUK MERAIH CAPABILITY LEVEL 5 PADA APO07}

\begin{tabular}{|c|c|}
\hline Atribut & Tindakan perbaikan \\
\hline $\begin{array}{c}\text { PA } 4.1 \\
\text { (process } \\
\text { measurement) }\end{array}$ & 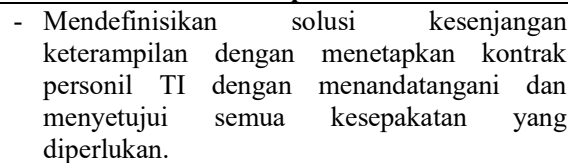 \\
\hline $\begin{array}{l}\text { PA } 4.2 \\
\text { (process } \\
\text { control) }\end{array}$ & $\begin{array}{l}\text { - Menyediakan akses ke repository pengetahuan } \\
\text { untuk mendukung pengembangan } \\
\text { keterampilan dan kompetensi dalam } \\
\text { mengelola SDM. }\end{array}$ \\
\hline $\begin{array}{c}\text { PA } 5.1 \\
\text { (process } \\
\text { innovation) }\end{array}$ & $\begin{array}{l}\text { - Mengembangkan dan mempertahankan } \\
\text { metode yang digunakan dalam mengelola } \\
\text { SDM. }\end{array}$ \\
\hline
\end{tabular}

\section{KESIMPULAN DAN SARAN}

Berdasarkan hasil penelitian tata kelola teknologi informasi pada Disnakertrans NTB, dapat ditarik kesimpulan sebagai berikut:

1. Hasil capability level untuk kondisi saat ini pada APO01 berada di tingkat 2 dan 3. Hal ini berarti sebagian besar proses dapat diulang, namun masih sangat bergantung kepada pengetahuan individu, sehingga kemungkinan terjadinya kesalahan yang cukup besar, dan proses dijalankan sesuai prosedur dan standar, terdokumentasi serta dikomunikasikan melalui pelatihan, tetapi pelaksanaanya diserahkan pada tim untuk mengikuti proses tersebut, sehingga tidak ada kekonsistenan.

2. Hasil capability level untuk kondisi saat ini pada APO07 berada di tingkat 1, level 2 dan level 3. Hal ini berarti pada Disnakertrans NTB sudah terdapat inisiatif untuk mengelola SDM tetapi belum ada SOP yang jelas untuk menjalankan proses tersebut sehingga untuk menjalankan fungsi dan layanan TI untuk kegiatan operasional sehari-hari masih bergantung pada individu yang mempunya kemampuan di bidang TI.

3. Hasil capability level untuk kondisi diharapkan pada APO01 dan APO07 berada di tingkat 4 dan 5 yang berarti manajemen pada Disnakertrans NTB akan menetapkan beberapa indikator untuk mengukur 
kinerja proses dan terdapat prosedur yang tetap untuk mengelola KKMTIdan mengelola SDM.

4. Rekomendasi dibuat untuk mengelola, memantau, dan mengevaluasi hasil kinerja staf TI. Pengelolaan teknologi informasi secara bertahap dimulai dari nilai capability level kondisi saat ini sampai kondisi yang diinginkan.

5. Rencana aksi yang diusulkan sudah dikonsultasikan dan disesuaikan dengan kebutuhan Disnakertrans NTB dan telah mendapat persejutuan serta memungkinkan untuk dapat digunakan dalam kebijakan pengelolaan teknologi informasi di Disnakertrans NTB.

6. Agar hasil tata kelola dapat lebih maksimal, instansi diharapkan dapat memadukan hasil penelitian serupa pada process goals yang lain, sehingga pada pelaksanaannya dapat lebih terintegrasi dan mendapatkan hasil yang maksimal.

\section{DAFTAR PUSTAKA}

[1] Disnakertrans NTB, "Rencana Strategis 20132018." Mataram, 2013.

[2] F. Muhafiizh, Suprapto, and R. I. Rokhmawati, "Evaluasi Sumber Daya Teknologi Informasi Perusahaan Menggunakan COBIT 5 (Studi Kasus : PT Krakatau Steel (Persero) Tbk.)," J. Pengemb. Teknol. Inf. dan Ilmu Komput., vol. 1, no. 12, pp.
1687-1696, 2017.

[3] I. ketut A. P. Pranata, Murahartawaty, and S. F. S. Gumilang, "Perancangan Tata Kelola Teknologi Informasi di PT. Industri Telekomunikasi Indonesia (Inti) Menggunakan Framework Cobit 5 pada Domain Align, Plan, and Organize (APO)," $J$. eProceeding Eng., vol. 2, no. 2, pp. 5431-5436, 2015.

[4] M. Afifuddin, S. Magister, M. Teknologi, and J. T. Informatika, "Perancangan Tata Kelola Teknologi Informasi Menggunakan Framework Cobit 5 di PT Sier," pp. 1-7, 2015.

[5] IT Governance Institute, Framework Control Objectives Management Guidelines Maturity Models. 2007.

[6] K. Surendro, Implementsi Tata Kelola Teknologi Informasi. Bandung: Informatika, 2009.

[7] I. P. A. Swastika and I. G. L. A. R. Putra, "Audit Sistem Informasi dan Tata kelola Teknologi Informasi.” Andi, Yogyakarta, 2016.

[8] ISACA, A Business Framework for the Governance and Management of Enterprice IT. USA: ISACA. 2012.

[9] J. F. Andry and K. Christianto, Audit Menggunakan COBIT 4.1 dan COBIT 5.0 dengan Case Study. Yogyakarta: Teknosain. 2016. .

[10] ISACA, "Enabling Processes.” ISACA, USA, 2012. 